\title{
Reliability of the Client-Centeredness of Goal Setting (C-COGS) Scale in Acquired Brain Injury Rehabilitation
}

\author{
Emmah Doig, Sarah Prescott, Jennifer Fleming, Petrea Cornwell, \\ Pim Kuipers
}

\section{MeSH TERMS}

- brain injuries

- goals

- person-centered therapy

- rehabilitation

- reproducibility of results

OBJECTIVE. To examine the internal reliability and test-retest reliability of the Client-Centeredness of Goal Setting (C-COGS) scale.

METHOD. The C-COGS scale was administered to 42 participants with acquired brain injury after completion of multidisciplinary goal planning. Internal reliability of scale items was examined using item-partial total correlations and Cronbach's $\alpha$ coefficient. The scale was readministered within a 1-mo period to a subsample of 12 participants to examine test-retest reliability by calculating exact and close percentage agreement for each item.

RESULTS. After examination of item-partial total correlations, test items were revised. The revised items demonstrated stronger internal consistency than the original items. Preliminary evaluation of test-retest reliability was fair, with an average exact percent agreement across all test items of $67 \%$.

CONCLUSION. Findings support the preliminary reliability of the C-COGS scale as a tool to evaluate and promote client-centered goal planning in brain injury rehabilitation.

Doig, E., Prescott, S., Fleming, J., Cornwell, P., \& Kuipers, P. (2016). Reliability of the Client-Centeredness of Goal Setting (C-COGS) scale in acquired brain injury rehabilitation. American Journal of Occupational Therapy, 70 , 7004290010. http://dx.doi.org/10.5014/ajot.2016.017046

Emmah Doig, PhD, BOccThy Hons, is Research Fellow, School of Health and Rehabilitation Sciences, University of Queensland, St. Lucia Campus, Brisbane, Australia; e.doig@uq.edu.au

Sarah Prescott, BOccThy Hons, is PhD Candidate, School of Health and Rehabilitation Sciences, University of Queensland, St. Lucia Campus, Brisbane, Australia.

Jennifer Fleming, PhD, BOccThy Hons, is Associate Professor, School of Health and Rehabilitation Sciences, University of Queensland, St. Lucia Campus; Occupational Therapy Department, Princess Alexandra Hospital, Brisbane, Australia; and Occupational Therapist, Centre for Functioning and Health Research, Metro South Health District, Queensland Health, Brisbane, Australia.

Petrea Cornwell, PhD, BSpPath Hons, is Principal Research Fellow, Metro North Hospital and Health Service, Department of Health, and School of Applied Psychology, Menzies Health Institute, Griffith University, Queensland, Australia, and Associate Professor, School of Allied Health Sciences, Griffith University, Brisbane, Australia.

Pim Kuipers, PhD, BA Hons, MA, Grad Dip Rehab, is Associate Professor, Centre for Functioning and Health Research, Metro South Health District, Queensland Health, and Centre of National Research on Disability and Rehabilitation Medicine, Griffith Health Institute, Griffith University, Brisbane, Australia.
$\mathrm{G}$ oal planning has been described as the essence of rehabilitation (Barnes \& Ward, 2000), and client-centeredness is evident in theories of goal planning. A client-centered goal-planning approach entails responding to individual client needs, involving the client in decision making, using active listening, and understanding and respecting the client and his or her knowledge and ability to make autonomous decisions (Bright, Boland, Rutherford, Kayes, \& McPherson, 2012; Cott, 2004; Hammell, 2013; Law, Baptiste, \& Mills, 1995; Mew \& Fossey, 1996). In addition, the central concepts of client-centeredness are the theoretical underpinnings of occupational therapy practice (Kielhofner, 2008; Law, 1998) and the core components of occupational therapy practice models. For example, the Person-Environment-Occupational Performance Model (Christiansen, Baum, \& Bass, 2011) requires active client involvement in determining intervention goals. Occupational therapy neurorehabilitation intervention models, such as the Dynamic Interactional Model of Cognition in Cognitive Rehabilitation (Toglia, 2011), recognize the importance of personal context, including a person's values, expectations, and motivation in planning rehabilitation. The neurofunctional approach to rehabilitation after brain injury requires rehabilitation targets to be determined by the client's functional goals (Giles, 2011).

According to goal-planning theories, motivation is moderated by goal importance and client commitment (Locke $\&$ Latham, 2002). In addition, Deci and Ryan's (1985) model of self-determination shows that extrinsic objectives 
(i.e., those imposed externally by others) are less motivating than intrinsically generated goals. Moreover, clients' direct involvement in goal planning results in better maintenance of treatment gains (Webb \& Glueckauf, 1994), greater perception that goals are relevant, more participation-level goals, and increased satisfaction with rehabilitation (Holliday, Cano, Freeman, \& Playford, 2007). Thus, evaluating goal-planning processes and goals from the client's perspective to enhance client participation in goal setting has the potential to inform rehabilitation practice and outcomes.

The purpose of this study was to examine the reliability of the Client-Centeredness of Goal Setting (C-COGS) scale (Doig, Prescott, Fleming, Cornwell, \& Kuipers, 2015) by investigating homogeneity and internal consistency of test items, test-retest reliability, and homogeneity of the Participation and Goals subscale items. We hypothesized that the C-COGS scale total score would be significantly positively associated with all scale items except Item 2 ("The goals are what my friend/relative wants me to work on") and Item 3 ("The goals are what my therapist wants me to work on") because we did not expect the views of significant others or therapists to be consistently aligned with client views on goals. Moreover, we hypothesized that Participation and Goals subscale items would most strongly correlate with their corresponding subscale total.

\section{C-COGS Scale}

The C-COGS scale was developed to promote and enhance client-centered goal planning through greater understanding of the client's perspective on planning processes and the resultant goals. The C-COGS scale is intended to be administered as soon as possible after goal planning is complete and rehabilitation goals are documented.

The initial version of the C-COGS scale was brief, comprising 4 items (Doig \& Fleming, 2014), and was developed to evaluate the perspectives of 14 clients with acquired brain injury (ABI) involved in a goal-directed intervention (Doig, Fleming, Kuipers, Cornwell, \& Khan, 2011). Later, taking into consideration the literature on client-centeredness and consumer feedback (Doig, Fleming, Cornwell, \& Kuipers, 2009), the C-COGS scale was expanded to 13 items. The scale's dimensionality (i.e., the number of factors, or dimensions, measured by an instrument) was determined theoretically; however, Meyer (2010) recommended further, empirical testing to determine dimensionality. Moreover, Velozo, Seel, Magasi, Heinemann, and Romero (2012) recommended that, in addition to qualitative methods such as literature reviews and interviews, statistical methods should be used to confirm dimensionality. The theoretical basis and development of the C-COGS scale are further outlined elsewhere (Doig et al., 2015).

The 13 C-COGS scale items (Figure 1) are grouped into three subscales (Alignment, Participation, and Goals) on the basis of the theoretical construct of clientcenteredness outlined in the literature and qualitative interviews (Meyer, 2010; Velozo et al., 2012). This grouping enhances practice evaluation by promoting reflection on three aspects of goal-planning practice: (1) alignment of client, practitioner, and significant other perceptions on goals and its impact on client decision making about goals; (2) client participation in goal planning; and (3) meaningfulness and importance of the resultant rehabilitation goals to the client. Each C-COGS scale item is rated on a 5 -point scale $(1=$ strongly disagree, $2=$ disagree, $3=$ unsure, $4=$ agree, $5=$ strongly agree) by the client to indicate his or her extent of agreement or disagreement with the item.

The Alignment subscale (Items 1-3) evaluates the extent to which the client, his or her significant others, and the practitioner perceive the goals discussed during goal planning as desirable or important. Because this subscale is descriptive, a subscale score is not calculated. However, the score for Item 1 ("The goals are what I want to work on") is included in calculating the total score because it relates to client-centeredness, in this case, the client's desire to work on goals.

The Participation subscale (Items 1 and 4-9) evaluates the client's perceived participation in goal planning and decision making about goals during their goal-planning sessions. Item 1 is included in this subscale because it

1. The goals are what I want to work on.

2. The goals are what my friend/relative wants me to work on.

3. The goals are what my therapist wants me to work on.

4. Significant people in my life (i.e., family, friends) were involved in planning the goals as much as I wanted them to be.

5. The therapist encouraged me to participate in setting the goals.

6. I was an active participant in the goal-setting session.

7. My views and opinions about the goals were listened to.

8. I felt like a partner in the goal-setting process (along with other people involved in my goal-setting sessions).

9. I made the final decision about which goals were set.

10. The goal is meaningful and important to me as it relates to who I am and my future.

11. The goal is relevant to my everyday life as it relates to what I want to do at home, work, or in the community.

12. The goal is what I am motivated to work on.

13. The goal is my own goal.

Figure 1. Client-Centeredness of Goal Setting (C-COGS) scale items.

Note. During administration of the C-COGS scale, Items 2-4 are to be explored in an interview format and are not included in the scoring of the scale. 
relates to client participation in goal planning. Scores may range from 7 to 35, with higher scores indicating greater perceived client-centeredness of goal planning.

The Goals subscale (Items 10-13) evaluates the meaningfulness, relevance, and ownership of the client's goals and the client's motivation to work on the goals. This subscale is administered after client goals have been finalized, and each goal is rated on each item. A score, ranging from 4 to 20 , is calculated for each goal. Then the average total subscale score is calculated by adding the scores for each goal and dividing the total by the number of goals. Higher scores indicate greater perceived client-centeredness of goals.

The C-COGS scale can be used by occupational therapy practitioners to enhance client goal planning through reflection on client responses and the reasons for their responses. Alignment subscale responses are intended to promote practitioners' reflection on how their involvement may influence clients' decision making and choices about goals and to promote discussion and education to enhance goal planning. Several qualitative studies of goal planning in stroke rehabilitation settings have found that therapists may direct the process and that goal planning can be influenced by contextual factors, such as therapists' perceived discharge priorities (Leach, Cornwell, Fleming, \& Haines, 2010; Levack, Dean, Siegert, \& McPherson, 2011). Participation subscale responses promote practitioner reflection about whether practitioner-client communication and client participation in discussions about goals could be improved. Goals subscale responses indicate whether the client perceives goals as meaningful and important to them.

Note that even when Participation subscale ratings are high, Goals subscale ratings may be low. For example, a client may report that he or she felt listened to and participated in goal planning; however, the client's documented goals may not reflect his or her desires. Therefore, practitioners can reflect on client responses and potentially enhance the client's satisfaction with his or her goals by determining the reasons for this gap. Some reasons may include poor goal documentation (e.g., the goal is not understood by the client) or service system factors that restrict working toward the client's desired goals (e.g., limited rehabilitation time frames or availability of equipment or resources).

\section{Method}

\section{Study Design}

This study used a prospective cross-sectional cohort design, with data collected from participants after goal planning and longitudinal data collected for a subset of participants.

\section{Participants}

Participants were eligible for inclusion if they were ages 18-65 yr, had a diagnosis of ABI, and were planning or reviewing their goals with their therapist. In addition, their treating therapist must have deemed them to have adequate cognitive and communication skills to provide informed consent and complete study questionnaires, and their treating therapist had to have also consented to be a study participant.

Participants were recruited between October 2013 and September 2014 while attending specialized outpatient ABI rehabilitation in a major metropolitan public hospital or private community-based therapy in Queensland, Australia. Sixty-nine potential participants were identified: 14 were referred from day hospitals, 4 were referred from private rehabilitation, and 51 were screened admissions. Of these potential participants, 13 declined and 14 were excluded ( 9 set no goals, 4 did not arrive for appointments, and 1 had a therapist who was not a participant). Thus, 42 participants consented to participate.

\section{Procedure}

Ethical clearance was obtained from relevant university and hospital research ethics committees. Each participant's goals were communicated to a researcher by the participant's treating therapist soon after goal planning. A researcher who was not involved with goal planning or delivering the rehabilitation program completed the C-COGS scale with participants either in person or by telephone within $24 \mathrm{hr}$ of the goals being established. During C-COGS scale administration, participants were prompted to reflect on their goal-planning sessions when responding to Items 1-9. Participants gave responses to Items 10-13 about each of their goals. The C-COGS scale was readministered to a subsample of 12 participants on average 6.7 days (standard deviation $[S D]=$ 10.5 days) after initial administration.

\section{Data Analysis}

All statistical analyses were performed using IBM SPSS Statistics (Version 20; IBM Corporation, Armonk, NY). Internal consistency of the 13 test items was evaluated using Cronbach's $\alpha$ coefficient. Coefficients approaching .90 indicate strong internal consistency, indicative of a reliable scale (Portney \& Watkins, 2009). Item-partial total correlations using Pearson product-moment correlations, whereby each item was correlated with the 
C-COGS scale total while omitting that item, were calculated to examine homogeneity (Streiner, Norman, \& Cairney, 2014). Recommendations outlined by Streiner and colleagues (2014) were followed whereby items with $r$ values less than .30 were eliminated and then internal consistency of retained items was reexamined. Scale items should be moderately correlated with the total score, ideally with $r$ no greater than .70 because greater correlations are likely an indication that items are too specific or narrow (Streiner et al., 2014). Item-partial total correlations using Pearson product-moment correlations were calculated to examine the homogeneity of retained items in the Participation and Goals subscales. Each subscale item was correlated with the corresponding subscale total while omitting that item and with the total of the other subscale (Streiner et al., 2014). Each item should ideally be moderately correlated $(r \leq .70)$ with its corresponding subscale total, and these correlations should exceed the item's correlations with scales in which it is not included (Streiner et al., 2014).

Because the C-COGS scale was readministered to only a small number of participants $(n=12)$, a conservative approach was taken to evaluate test-retest reliability by calculating percent exact agreement (i.e., the same rating for both time points) and percent close agreement (i.e., either the same rating for or a 1-point difference between both time points) between Time 1 and Time 2 for each item across participants. For Items 10-13, agreement was calculated by comparing responses between the two time points for each goal.

\section{Results}

\section{Participant Characteristics}

Participant characteristics, including demographic data, injury severity, and mechanism of injury, are outlined in Table 1. Participants with traumatic brain injury were classified as having a mild, moderate, or severe injury on the basis of their length of posttraumatic amnesia (PTA) or Glasgow Coma Scale (GCS; Teasdale \& Jennett, 1974) score when PTA was not available. Duration of PTA has been shown to be more predictive of outcome than the GCS (Cattelani, Tanzi, Lombardi, \& Mazzucchi, 2002; Willemse-van Son, Ribbers, Verhagen, \& Stam, 2007), but PTA was not always formally assessed in our participant group. Therapist participants included 4 private therapy providers $(1$ speech therapist and 3 occupational therapists) and 15 day hospital therapists (4 physiotherapists, 5 occupational therapists, 4 speech therapists, 1 social worker, and 1 neuropsychologist). Therapists had been qualified in their profession on average for $13.9 \mathrm{yr}$ $(S D=10.4 \mathrm{yr})$ and had worked in ABI rehabilitation on average for $8.9 \mathrm{yr}(S D=6.9)$.

A total of sixty-four sets of goals were planned with participants: in occupational therapy, 36; in speech therapy, 17; in physiotherapy, 7; during social work, 3; and during neuropsychology, 1 . Several participants attended multiple therapies, and the number of goals per participant ranged from $1(n=2)$ to $6(n=3)$, with 3 or 4 goals being the most common $(n=47)$.

\section{Internal Consistency Reliability}

Cronbach's $\alpha$ coefficient for the 13 items was $.82(x=$ $55.19, S D=5.7)$, approaching strong internal consistency.

Table 1. Participant Demographics $(N=42)$

\begin{tabular}{|c|c|}
\hline Characteristic & $n$ or $M(S D)$ \\
\hline Age, yr & 37.8 (12.8) \\
\hline \multicolumn{2}{|l|}{ Gender } \\
\hline Female & 14 \\
\hline Male & 28 \\
\hline Education, yr $(n=41)$ & $13.1 \quad(2.5)$ \\
\hline \multicolumn{2}{|l|}{ Ethnicity (ASCCEG; $n=41$ ) } \\
\hline Oceanian & 35 \\
\hline North West European & 2 \\
\hline Southern and Eastern European & 2 \\
\hline Sub-Saharan African & 2 \\
\hline \multicolumn{2}{|l|}{ Primary preinjury occupation (ANZSCO) } \\
\hline Manager or professional & 10 \\
\hline Technical/trade & 10 \\
\hline Community/personal service & 3 \\
\hline Clerical/administrative & 7 \\
\hline Sales or laborer & 2 \\
\hline Student & 7 \\
\hline Unemployed or retired & 3 \\
\hline \multicolumn{2}{|l|}{ Diagnosis } \\
\hline $\mathrm{TBI}$ & 24 \\
\hline Stroke & 6 \\
\hline SAH or SDH & 5 \\
\hline Hypoxia or tumor & 4 \\
\hline Other & 3 \\
\hline Initial GCS score for participants with TBI $(n=19)$ & $7.6 \quad(4.4)$ \\
\hline \multicolumn{2}{|l|}{ TBI severity } \\
\hline Mild (PTA 0-1 days or GCS 13-15) & 4 \\
\hline Moderate (PTA >1-7 days or GCS 9-12) & 2 \\
\hline Severe (PTA >7 days or GCS 3-8) & 16 \\
\hline PTA length or GCS score unavailable & 2 \\
\hline \multicolumn{2}{|l|}{ Inpatient rehabilitation } \\
\hline Yes & 27 \\
\hline Length of stay, days & $59.6(56.6)$ \\
\hline No & 15 \\
\hline Time since injury, days & $299.2(392.1)$ \\
\hline
\end{tabular}

Note. ASCCEG = Australian Standard Classification of Cultural and Ethnic Groups; ANZSCO = Australian and New Zealand Standard Classification of Occupations; GCS = Glasgow Coma Scale; $M=$ mean; PTA = posttraumatic amnesia, $\mathrm{SAH}=$ subarachnoid hemorrhage; $S D=$ standard deviation; $\mathrm{SDH}=$ subdural hemorrhage; $\mathrm{TBI}=$ traumatic brain injury. 
Examination indicated poor item-partial total correlations $(r<.30)$ for Items 2 and 3, as hypothesized, and for Item 4 (Table 2). Thus, these items were excluded from the scoring of the scale. The 10 retained items comprised the Participation (Items 1 and 5-9) and Goals (Items 10-13) subscales (see Figure 1). Item-partial total correlations were mostly moderately correlated, with $r$ values ranging from .49 to .79 , and all item-partial total correlations were significant at $p<.01$. Internal consistency of the revised 10 -item scale was strong, with a Cronbach's $\alpha$ coefficient of .94 $(x=44.7, S D=4.7)$.

The retained Participation subscale items were all significantly $(p<.01)$ and moderately $(r=.61-.80)$ correlated, demonstrating higher correlations with the Participation subscale total compared with the Goals subscale total for Items 5 and 7-9. Items 1 and 6 showed slightly higher correlations with the Goals subscale. The Goals subscale items were significantly and moderately to highly correlated with the Goals subscale total $(p<.01$, $r=.79-.86$ ), demonstrating higher correlations with the Goals subscale total compared with the Participation subscale total for Items 10-12; Item 13 was equally correlated with both subscales.

\section{Test-Retest Reliability}

Percent agreement between Time 1 and Time 2 ratings for each of the 13 items across 12 participants is reported in
Table 2. Percent exact agreement ranged from $17 \%$ to $87 \%$. Item 2 demonstrated low percent exact agreement, with only 2 participants rating this item the same both times. However, from Time 1 to Time 2, 11 out of 12 participants rated this item the same or with a 1-point difference. Average percent exact agreement across all items was $67 \%$. Percent close agreement ranged from $75 \%$ to $100 \%$, indicating that the majority of item ratings were either exactly the same or 1 point different on retesting.

\section{Discussion}

This study explored internal consistency and test-retest reliability of the $\mathrm{C}-\mathrm{COGS}$ scale by using a relatively large group of people with $\mathrm{ABI}$ in an outpatient rehabilitation setting. The C-COGS scale was designed to promote clinical reflection about and evaluation of client-centered goal planning. The findings confirm inclusion of most items in the scoring of the scale, with Items 2-4 recommended to be retained only as descriptive items for clinical evaluation. Therefore, occupational therapy practitioners should explore these items with their clients only in an interview format because further psychometric evaluation of the reliability of these items needs to be undertaken before they can be considered for inclusion as scale items.

Preliminary test-retest reliability findings indicated that most test items were rated consistently at scale

Table 2. Item-Partial Total Correlations and Test-Retest Reliability

\begin{tabular}{|c|c|c|c|c|c|c|}
\hline \multirow[b]{2}{*}{ Item } & \multirow[b]{2}{*}{$M(S D)$} & \multicolumn{3}{|c|}{ Item-Partial Total Correlation $(r)$} & \multicolumn{2}{|c|}{ Test-Retest Reliability (\%) } \\
\hline & & $\begin{array}{c}\text { C-COGS } \\
\text { Scale } \\
(n=64)\end{array}$ & $\begin{array}{l}\text { Participation } \\
\text { Subscale } \\
(n=64)\end{array}$ & $\begin{array}{c}\text { Goals } \\
\text { Subscale } \\
(n=64)\end{array}$ & $\begin{array}{c}\text { Exact } \\
\text { Agreement } \\
(n=12)\end{array}$ & $\begin{array}{c}\text { Close } \\
\text { Agreement } \\
(n=12)\end{array}$ \\
\hline 1. "The goals are what I want to work on." & $4.56(0.5)$ & $.58^{\star *}$ & $.61^{* *}$ & $.64^{\star *}$ & 83 & 100 \\
\hline 2. "The goals are what my friend/relative wants me to work on." & $3.04(1.3)$ & .16 & - & - & 17 & 92 \\
\hline 3. "The goals are what my therapist wants me to work on." & $3.64(1.2)$ & .17 & - & - & 58 & 92 \\
\hline $\begin{array}{l}\text { 4. "Significant people in my life (i.e., family, friends) were } \\
\text { involved in planning the goals as much as I wanted them to be." }\end{array}$ & $3.78(1.1)$ & $.29^{*}$ & - & - & 42 & 75 \\
\hline 5. "The therapist encouraged me to participate in setting the goals." & $4.39(0.6)$ & $.61^{* *}$ & $.74^{\star *}$ & $.60^{* *}$ & 75 & 100 \\
\hline 6. "I was an active participant in the goal-setting session." & $4.51(0.6)$ & $.69^{* *}$ & $.75^{\star *}$ & $.83^{* *}$ & 75 & 100 \\
\hline 7. "My views and opinions about the goals were listened to." & $4.44(0.6)$ & $.49^{* \star}$ & $.61^{* *}$ & $.60^{* *}$ & 75 & 100 \\
\hline $\begin{array}{l}\text { 8. "I felt like a partner in the goal-setting process (along with } \\
\text { other people involved in my goal-setting sessions)." }\end{array}$ & $4.45(0.6)$ & $.66^{* *}$ & $.71^{\star *}$ & $.67^{\star *}$ & 75 & 100 \\
\hline 9. "I made the final decision about which goals were set." & $4.47(0.6)$ & $.58^{\star *}$ & $.65^{\star *}$ & $.60^{* *}$ & 58 & 100 \\
\hline $\begin{array}{l}\text { 10. "The goal is meaningful and important to me as it relates } \\
\text { to who I am and my future." }\end{array}$ & $4.51(0.5)$ & $.79^{* *}$ & $.73^{\star *}$ & $.86^{* *}$ & 87 & 100 \\
\hline $\begin{array}{l}\text { 11. "The goal is relevant to my everyday life as it relates to what } \\
\text { I want to do at home, work, or in the community." }\end{array}$ & $4.45(0.6)$ & $.76^{\star \star}$ & $.71^{\star \star}$ & $.84^{\star \star}$ & 68 & 97 \\
\hline 12. "The goal is what I am motivated to work on." & $4.45(0.6)$ & $.74^{\star \star}$ & $.80^{* *}$ & $.85^{\star *}$ & 71 & 95 \\
\hline 13. "The goal is my own goal." & $4.48(0.5)$ & $.75^{\star \star}$ & $.79^{\star \star}$ & $.79^{\star \star}$ & 71 & 97 \\
\hline
\end{tabular}

Note. During administration of the C-COGS scale, Items 2-4 are to be explored in an interview format and are not included in the scoring of the scale. Correlations for Items 10-13 were calculated using the average response across all goals for each participant. Percentage agreement for test-retest reliability for Items 10-13 was calculated for each goal (total goals $=38$ ). Close agreement is defined as a follow-up rating that is the same as the initial rating or that has a 1-point difference from the initial rating. $-=$ excluded from scoring; C-COGS = Client-Centeredness of Goal Setting; $M=$ mean; $S D=$ standard deviation.

${ }^{*} p<.05 .{ }^{* \star} p<.01$. 
readministration, which was on average 1 wk after initial administration. Test-retest reliability (exact agreement) for Items 2-4 was significantly lower compared with the majority of other items, which lends further support for separating these items from the scoring of the scale.

As expected, the item-partial total correlations for Items 2 and 3 were weak and not significant. These items were not designed to measure the client-centeredness of goal planning but rather to explore the client's perceptions about practitioner and family views. The item-partial total correlation for C-COGS scale Item 4 was also weak, with scores for this item typically rated lower $(x=3.78)$ compared with other items. Responses for this item, which rates family involvement in goal planning, varied across participants, with many reporting a desire for more family involvement in goal planning. Participants reported various reasons for nonparticipation of families in goal planning, including family time constraints and work commitments. Some participants also reported that they were not aware that family members could be involved in goal planning.

Previous qualitative findings exploring family perspectives of $\mathrm{ABI}$ rehabilitation in day hospital settings indicated that a barrier to family participation may be that members feel like intruders in the clinical setting (Doig et al., 2009). Although scores for Items $2-4$ were not consistent with the other retained items in the scale, they are important for service evaluation purposes because they relate to family and service provider involvement in goal planning.

Families are often consulted during goal planning in ABI rehabilitation settings to enhance understanding of clients who have cognitive or communication impairments, support the client, and facilitate education (Doig et al., 2009; Hale, 2010; Leach et al., 2010; Levack, Siegert, Dean, \& McPherson, 2009). However, family involvement can be either positive or negative. An example of a negative consequence of family involvement is that the goal-planning process may be inhibited if family members impose their goals (Levack et al., 2009). Client responses to Items 2-4 may enable practitioners to pinpoint family-related barriers to client-centered goal planning and promote discussion about positive family involvement. Moreover, practitioners should also document clients' qualitative responses to these items and ask open-ended questions to enhance clinical reflection and understanding of clients' perspectives, such as, "Are the goals what you truly want to work on?" and "Was your goal choice influenced by what you feel others want you to work on?"

This study provides preliminary data on test-retest reliability that indicates that most items were rated consistently by most participants between two time points. However, the test-retest interval was lengthy for some participants (range, $1-35$ days; mean $=6.75$ days); therefore, testretest reliability could be underestimated, particularly for items requiring recall of discussions with therapists during goal-planning sessions. In addition, views about goals also may have changed over this time period. Moreover, establishing reliability can be challenging for a scale with few test items and difficult to do in a population with ABI because cognitive deficits may affect responses given at different time points. Therefore, in examining test-retest reliability, we calculated close agreement, showing positive preliminary findings.

Future research should include administering this scale to larger samples and implementing shorter retest time intervals to more thoroughly examine test-retest reliability. Because this study also examined internal reliability of the subscale items, future research should examine factor structure to determine whether the same subscales are supported using a larger sample. Further research is also recommended to examine strategies that facilitate client-centered goal planning. Use of the C-COGS scale in such research may enable empirical measurement of the client-centeredness of goal-planning approaches. Strategies and measures to support greater goal ownership, motivation, and choice of goals that are most important and meaningful to clients are an important step. In addition, where client, service provider, and contextual factors pose challenges to the client-centeredness of goals, enhanced measures will be particularly useful.

\section{Implications for Occupational Therapy Practice}

The results of this study have the following implications for occupational therapy practice:

- The C-COGS scale provides brain injury rehabilitation practitioners an opportunity to reflect on goalplanning practices to promote and enhance client participation in goal setting and on the importance and meaningfulness of rehabilitation goals to clients.

- The C-COGS scale demonstrates preliminary reliability and may be used to empirically evaluate client participation in goal planning and goal importance and meaning.

\section{Conclusion}

The C-COGS scale can be used to evaluate goal planning from the client's perspective and is intended for use by clinicians to enhance multidisciplinary goal planning and 
as a research measure exploring factors that contribute to successful rehabilitation. The scale was developed for use by all professionals working with people in rehabilitation settings and can be used by occupational therapy practitioners to evaluate and enhance client-centered goalplanning practice. In addition, the study findings provide preliminary evidence to support reliability of the C-COGS scale.

\section{Acknowledgments}

This research was conducted with the assistance of a Community Rehabilitation Workforce Project Grant from the Division of Rehabilitation at the Princess Alexandra Hospital. The first author conducted this research with the assistance of a National Health and Medical Research Council postdoctoral research fellowship awarded by the Centre for Research Excellence in Brain Recovery (Grant No. 1023043).

\section{References}

Barnes, M. D., \& Ward, A. B. (2000). Textbook of rehabilitation medicine. Oxford, England: Oxford University Press.

Bright, F. A., Boland, P., Rutherford, S. J., Kayes, N. M., \& McPherson, K. M. (2012). Implementing a client-centred approach in rehabilitation: An autoethnography. Disability and Rehabilitation, 34, 997-1004. http://dx.doi.org/10. 3109/09638288.2011.629712

Cattelani, R., Tanzi, F., Lombardi, F., \& Mazzucchi, A. (2002). Competitive re-employment after severe traumatic brain injury: Clinical, cognitive and behavioural predictive variables. Brain Injury, 16, 51-64. http://dx.doi.org/10.1080/ 02699050110088821

Christiansen, C., Baum, C. M., \& Bass, J. (2011). The PersonEnvironment-Occupational Performance Model. In E. A. S. Duncan (Ed.), Foundations for practice in occupational therapy (5th ed., pp. 93-104). London: Elsevier.

Cott, C. A. (2004). Client-centred rehabilitation: Client perspectives. Disability and Rehabilitation, 26, 1411-1422. http://dx.doi.org/10.1080/09638280400000237

Deci, E., \& Ryan, R. (1985). Intrinsic motivation and selfdetermination in human behavior. New York: Plenum Press. http://dx.doi.org/10.1007/978-1-4899-2271-7

Doig, E., \& Fleming, J. (2014). An occupation-based, clientcentred approach to goal planning and measurement. In R. J. Seigert \& W. M. M. Levack (Eds.), Rehabilitation goal setting: Theory, practice and evidence (1st ed., pp. 181-211). Boca Raton, FL: Taylor \& Francis.

Doig, E., Fleming, J., Cornwell, P. L., \& Kuipers, P. (2009). Qualitative exploration of a client-centered, goal-directed approach to community-based occupational therapy for adults with traumatic brain injury. American Journal of Occupational Therapy, 63, 559-568. http://dx.doi.org/10. 5014/ajot.63.5.559

Doig, E. J., Fleming, J., Kuipers, P., Cornwell, P., \& Khan, A. (2011). Goal-directed outpatient rehabilitation following
TBI: A pilot study of programme effectiveness and comparison of outcomes in home and day hospital settings. Brain Injury, 25, 1114-1125. http://dx.doi.org/10.3109/ 02699052.2011.607788

Doig, E., Prescott, S., Fleming, J., Cornwell, P., \& Kuipers, P. (2015). Development and construct validation of the Client-Centredness of Goal Setting (C-COGS) scale. Scandinavian Journal of Occupational Therapy, 22, 302-310. http://dx.doi.org/10.3109/11038128.2015.1017530

Giles, G. M. (2011). A neurofunctional approach to rehabilitation after brain injury. In N. Katz (Ed.), Cognition, occupation, and participation across the life span: Neuroscience, neurorehabilitation, and models of intervention in occupational therapy (3rd ed., pp. 351-382). Bethesda, MD: AOTA Press.

Hale, L. (2010). Goal Attainment Scaling in physiotherapeutic home-based stroke rehabilitation. Advances in Physiotherapy, 12, 142-149. http://dx.doi.org/10.3109/14038196. 2010.486040

Hammell, K. R. (2013). Client-centred occupational therapy in Canada: Refocusing on core values. Canadian Journal of Occupational Therapy, 80, 141-149. http://dx.doi.org/10. 1177/0008417413497906

Holliday, R. C., Cano, S., Freeman, J. A., \& Playford, E. D. (2007). Should patients participate in clinical decision making? An optimised balance block design controlled study of goal setting in a rehabilitation unit. Journal of Neurology, Neurosurgery, and Psychiatry, 78, 576-580. http://dx. doi.org/10.1136/jnnp.2006.102509

Kielhofner, G. (2008). Introduction to the Model of Human Occupation. In G. Kielhofner (Ed.), Model of Human Occupation: Theory and application (4th ed., pp. 1-8). Baltimore: Lippincott Williams \& Wilkins.

Law, M. (Ed.). (1998). Client-centered occupational therapy. Thorofare, NJ: Slack.

Law, M., Baptiste, S., \& Mills, J. (1995). Client-centered rehabilitation: What does it mean and does it make a difference? Canadian Journal of Occupational Therapy, 62, 250-257. http://dx.doi.org/10.1177/000841749506200504

Leach, E., Cornwell, P., Fleming, J., \& Haines, T. (2010). Patient centered goal-setting in a subacute rehabilitation setting. Disability and Rehabilitation, 32, 159-172. http:// dx.doi.org/10.3109/09638280903036605

Levack, W. M., Dean, S. G., Siegert, R. J., \& McPherson, K. M. (2011). Navigating patient-centered goal setting in inpatient stroke rehabilitation: How clinicians control the process to meet perceived professional responsibilities. Patient Education and Counseling, 85, 206-213. http://dx. doi.org/10.1016/j.pec.2011.01.011

Levack, W., Siegert, R., Dean, S., \& McPherson, K. (2009). Goal planning for adults with acquired brain injury: How clinicians talk about involving family. Brain Injury, 23, 192-202. http://dx.doi.org/10.1080/02699050802695582

Locke, E. A., \& Latham, G. P. (2002). Building a practically useful theory of goal setting and task motivation: A 35year odyssey. American Psychologist, 57, 705-717. http:// dx.doi.org/10.1037/0003-066X.57.9.705

Mew, M. M., \& Fossey, E. (1996). Client-centred aspects of clinical reasoning during an initial assessment using the 
Canadian Occupational Performance Measure. Australian Occupational Therapy Journal, 43, 155-166. http://dx.doi. org/10.1111/j.1440-1630.1996.tb01851.x

Meyer, P. (2010). Understanding measurement: Reliability. New York: Oxford University Press. http://dx.doi.org/10.1093/ acprof:oso/9780195380361.001.0001

Portney, L. G., \& Watkins, M. P. (2009). Foundations of clinical research applications to practice (3rd ed.). Upper Saddle River, NJ: Pearson Prentice Hall.

Streiner, D. L., Norman, G. R., \& Cairney, J. (2014). Health measurement scales: A practical guide to their development and use (5th ed.). Oxford, England: Oxford University Press.

Teasdale, G. M., \& Jennett, B. (1974). Assessment of coma and impaired consciousness. Lancet, 2, 81-84.

Toglia, J. (2011). The Dynamic Interactional Model of Cognition in Cognitive Rehabilitation. In N. Katz (Ed.), Cognition, occupation, and participation across the life span: Neuroscience, neurorehabilitation, and models of interven- tion in occupational therapy (3rd ed., pp. 161-202). Bethesda, MD: AOTA Press.

Velozo, C. A., Seel, R. T., Magasi, S., Heinemann, A. W., \& Romero, S. (2012). Improving measurement methods in rehabilitation: Core concepts and recommendations for scale development. Archives of Physical Medicine and Rehabilitation, 93(Suppl.), S154-S163. http://dx.doi.org/ 10.1016/j.apmr.2012.06.001

Webb, P. M., \& Glueckauf, R. L. (1994). The effects of direct involvement in goal setting on rehabilitation outcomes for persons with traumatic brain injuries. Rehabilitation Psychology, 39, 179-188. http://dx.doi.org/10.1037/h0080321

Willemse-van Son, A. H. P., Ribbers, G. M., Verhagen, A. P., \& Stam, H. J. (2007). Prognostic factors of long-term functioning and productivity after traumatic brain injury: A systematic review of prospective cohort studies. Clinical Rehabilitation, 21, 1024-1037. http://dx.doi.org/10.1177/ 0269215507077603 
Reproduced with permission of the copyright owner. Further reproduction prohibited without permission. 